\title{
Weight Loss After Bariatric Surgery in Morbidly Obese End-Stage Kidney Disease Patients as Preparation for Kidney Transplantation. Matched Pair Analysis in a High-Volume Bariatric and Transplant Center
}

\author{
Małgorzata Dobrzycka $^{1}$ • Monika Proczko-Stepaniak ${ }^{1}$ • Łukasz Kaska ${ }^{1}$ • Maciej Wilczyński ${ }^{1}$ - Alicja Dębska-Ślizień ${ }^{2}$. \\ Jarosław Kobiela ${ }^{1}$
}

Published online: 5 April 2020

(C) The Author(s) 2020

\begin{abstract}
Background The number of morbidly obese kidney transplant candidates is growing. They have limited access to kidney transplantation and are at a higher risk of postoperative complications. Bariatric surgery is considered as a safe weight loss method in those patients.

Objectives Matched pair analysis was designed to analyze the preparatory and postoperative weight loss after bariatric procedures in end-stage kidney disease (ESKD) and non-ESKD morbidly obese patients.

Methods Twenty patients with ESKD underwent bariatric surgery in our Centre of Excellence for Bariatric and Metabolic Surgery between 2015 and 2019 (nine one-anastomosis gastric bypasses, nine Roux-en-Y gastric bypasses, and two sleeve gastrectomies). They were compared with matched pairs from a dataset of 1199 morbidly obese patients without ESKD. Data on demographic factors and comorbidities was recorded. BMI was obtained at the start of the preparatory period preceding the bariatric procedure, at the time of procedure, and during the 1-year follow-up.

Results The ESKD and non-ESKD patients did not differ significantly in preoperative weight loss $(13.00 \pm 11.69 \mathrm{~kg}$ and $15.22 \pm$ $15.96 \mathrm{~kg}$ respectively, $p=0.619)$. During the 1 -year follow-up, the weight loss was similar to the non-ESKD group. In the first 3 months, faster weight loss in ESKD was observed. Initial and follow-up BMI values did not differ significantly between groups. We demonstrated that obese patients with ESKD can lose weight as effectively as non-ESKD patients.

Conclusion Morbidly obese ESKD patients have an equal weight loss to patients without ESKD. Bariatric surgery could improve access to kidney transplantation and may potentially improve transplantation outcomes of obese patients with ESKD.
\end{abstract}

Keywords Bariatric surgery $\cdot$ Kidney transplantation $\cdot$ End-stage kidney disease $\cdot$ Weight loss

\section{Introduction}

Obesity is a growing problem worldwide. The prevalence of obesity has doubled since 1980, and now, nearly a third of the world's population is classified as overweight or obese.

Małgorzata Dobrzycka

malgorzata.dobrzycka@gumed.edu.pl

1 Department of General, Endocrine and Transplant Surgery, Medical University of Gdansk, Gdansk, Poland

2 Department of Nephrology and Transplant Medicine, Medical University of Gdansk, Gdansk, Poland
Obesity is associated with numerous comorbidities including diabetes type 2, peripheral vascular disease, cardiovascular disease, asthma, and osteoarthritis and was shown to be an independent risk factor for developing an end-stage kidney disease (ESKD) [1, 2]. Moreover, the relative risk correlates with a higher body mass index (BMI). The risk of ESKD progression was also increased by obesity [3]. Due to the obesity epidemic, the number of obese transplant candidates has also increased. Nearly $60 \%$ of all kidney transplant recipients are overweight or obese with male predominance [4]. It was proven that obesity limits, or at least delays, access to kidney transplantation [5]. Bariatric surgery is considered a safe method to achieve rapid and sustainable weight loss before kidney transplantation [6]. Pretransplant weight loss may 
allow to sustain body weight and prevent common posttransplant weight gain [7]. In the current study, we compare the preoperative and postoperative weight loss in patients with ESKD with matched controls without ESKD treated with bariatric surgery in a high-volume bariatric and transplant center.

\section{Subjects and Methods}

We have compared retrospectively the dynamics of weight loss of patients with and without ESKD who underwent bariatric surgery in a large bariatric and transplant center. In our institutional registries, 20 patients with ESKD were treated for morbid obesity between 2015 and 2019. ESKD was defined as the presence of an estimated glomerular filtration rate less than $15 \mathrm{~mL} / \mathrm{min} / 1.7 \mathrm{~m}^{2}[8]$.

For the purpose of this analysis, patients were matched for age, gender, and type of surgery with 20 patients without ESKD from our institutional dataset of 1199 patients. Matching was executed in a 1 to 1 ratio based on data queries. Data analysis included patient's demographics. The ESKD patients (14 males, 6 females) were between 42 and 64 years of age. The non-ESKD group consisted of 14 males and 6 females between 42 and 64 years of age. Body weight $(\mathrm{kg})$ and body height $(\mathrm{m})$ were used to calculate BMI. All patients were qualified to bariatric procedure according to IFSO guidelines after a multidisciplinary consultation [9]. Patients were qualified to surgery if their BMI exceeded $40 \mathrm{~kg} / \mathrm{m}^{2}$ or they had BMI between 35 and $40 \mathrm{~kg} / \mathrm{m}^{2}$ with significant comorbidities. The preoperative diet plan is exercised under the supervision of a dietitian. It is designed to give approximately $100 \mathrm{~g}$ of carbohydrate per day, low in fat and moderate in protein. The energy value of the diet is between 800 and $1000 \mathrm{kcal}$ per day. Two weeks before surgery, a livershrinking diet (600 kcal per day) was administered. ESKD patients had consulted with a nephrologist and undergone hemodialysis without heparin 1 day before surgery and on postoperative day 1 . They do not require distinctions in anesthesia compared with the non-ESKD group. Postoperatively, routine thromboembolism prophylaxis with dalteparin sodium (5000 IU subcutaneous) was conducted except on the days with hemodialysis. The maximal BMI was calculated from maximal body weight at the start of the preparatory period for bariatric treatment. The initial BMI was calculated from the weight at the time of surgery after an obligatory weight loss period with the low-calorie diet. Three bariatric procedures were performed according to our institutional regulations by the same surgeons [10]. The follow-up measurements were performed during routine follow-up in the outpatient department $1,3,6$, and 12 months after surgery.

Weight loss was reported according to the American Society for Metabolic and Bariatric Surgery (ASMBS) guidelines [11]. The change in BMI $(\Delta \mathrm{BMI})$ was calculated according to the formula $=($ initial $\mathrm{BMI})-($ postoperative BMI on each follow-up point). The $\%$ of reduction of BMI was calculated according to the formula = follow-up BMI/ initial BMI $\times 100 \%$ on each follow-up point. The percentage of excess BMI loss (\%EBMIL) was calculated using the formula $=[\Delta \mathrm{BMI} /($ Initial BMI -25$)] \times 100 \%[11]$. In the preparatory period, we used maximal BMI to calculate \%EBMIL.

\section{Statistical Analysis}

Statistical analyses were performed using the Statistica 13.3 Software (TIBCO Software Inc.). Data was presented as mean \pm standard deviation. The $\mathrm{Chi}^{2}$ and t-tests were used for comparisons. Statistical significance was considered for $p<0.05$. The graphs were drawn in the Microsoft Excel software.

\section{Results}

Baseline demographic characteristics of the patients are presented in Table 1.

\section{ESKD Group}

The ESKD patients' mean maximal weight was $128 \pm 18.5 \mathrm{~kg}$ and was reduced to $115 \pm 14.5 \mathrm{~kg}$ preoperatively. In the preparatory period, a $10 \%$ reduction of body weight was achieved. Mean maximal BMI was $42.8 \mathrm{~kg} / \mathrm{m}^{2}$; the initial BMI was $38.5 \mathrm{~kg} / \mathrm{m}^{2}$. In the baseline characteristics of ESKD, a higher incidence of hypertension was noted $(70 \%$ vs $35 \%, p=0.027$ ). OAGB (one-anastomosis gastric bypass) was performed in 9/20 patients (45\%), RYGB (Roux-en-Y gastric bypass) in $9 / 20$ patients (45\%), LSG (laparoscopic sleeve gastrectomy) in $2 / 20$ patients $(10 \%)$. In the ESKD group, one serious complication on the first postoperative day after OAGB was noted. The patient required revision surgery for a leak at the gastrojejunal anastomosis, which was identified and sutured. In ESKD patients, the length of hospital stay was $3.8 \pm 0.5$ day (excluded one case with LOS of 26 days).

\section{Matched Non-ESKD Group}

The non-ESKD patients' mean maximal weight was $131.5 \pm$ $20.5 \mathrm{~kg}$ and was reduced to $116.3 \pm 14.5 \mathrm{~kg}$ preoperatively. In the control group, a $12 \%$ reduction of weight was achieved, compared with $10 \%$ in the study group $(p=0.619)$. Mean maximal BMI was $43.6 \mathrm{~kg} / \mathrm{m}^{2}$; the initial BMI was $38.4 \mathrm{~kg} /$ $\mathrm{m}^{2}$. There were no surgical complications in that group. The LOS was $2.1 \pm 0.5$ day. 
Table 1 Baseline demographic characteristics of the patients

\begin{tabular}{llll}
\hline & ESKD group $(n=20)$ & Non-ESKD group $(n=20)$ & $p^{*}$ \\
\hline Gender (male/female) & $70 / 30 \%$ & $70 / 30 \%$ & $\mathrm{n} / \mathrm{a}$ \\
Dialysis type & & & \\
Hemodialysis & $16(80 \%)$ & 0 & $\mathrm{n} / \mathrm{a}$ \\
Peritoneal dialysis & $2(10 \%)$ & 0 & $\mathrm{n} / \mathrm{a}$ \\
Preemptive & $2(10 \%)$ & 0 & $\mathrm{n} / \mathrm{a}$ \\
ESKD etiology & & & $\mathrm{n} / \mathrm{a}$ \\
Diabetes mellitus & 4 & 0 & $\mathrm{n} / \mathrm{a}$ \\
Hypertension & 3 & 0 & $\mathrm{n} / \mathrm{a}$ \\
Glomerulonephritis & 4 & 0 & $\mathrm{n} / \mathrm{a}$ \\
ADPKD & 3 & 0 & $\mathrm{n} / \mathrm{a}$ \\
Unknown & 6 & $7(35 \%)$ & \\
Comorbidities & & $10(50 \%)$ & 0.027 \\
Hypertension & $14(70 \%)$ & $2(10 \%)$ & 0.525 \\
Diabetes mellitus type 2 & $12(60 \%)$ & 0 & 0.212 \\
Hyperlipidemia & $5(25 \%)$ & $1(5 \%)$ & \\
Coronary disease & $6(30 \%)$ & $3(15 \%)$ & 0.548 \\
Obstructive sleep apnea & $2(10 \%)$ & $1(5 \%)$ & 1 \\
Gastrointestinal reflux disease & $3(15 \%)$ & 0 & 0.340 \\
Chronic obstructive pulmonary disease & $4(20 \%)$ & $10(50 \%)$ & 0.751 \\
Cardiac rhythm abnormalities & $4(20 \%)$ & & \\
Previous surgeries & $12(60 \%)$ & & \\
\hline
\end{tabular}

*Chi ${ }^{2}$ test was used for all comparisons

\section{Comparisons}

The maximal weight did not differ significantly between ESKD and non-ESKD groups $(128 \pm 18.5 \mathrm{~kg}$ vs $131.5 \pm$ $20.5 \mathrm{~kg}$ respectively, $p=0.583$ ). The maximal BMI did not differ significantly $\left(43.2 \mathrm{~kg} / \mathrm{m}^{2}\right.$ vs $43.6 \mathrm{~kg} / \mathrm{m}^{2}$ respectively, $p=0.66$ ). The change in BMI in the preparatory period was similar between the groups (4.36 vs 5.13 respectively, $p=$ $0.6)$. The characteristics of follow-up measurements were presented in Table 2.

Bariatric surgery resulted in weight loss compared on four follow-up points. The comparison of \%EBMIL in ESKD and non-ESKD patients is illustrated in Fig. 1.

\section{Discussion}

In this study, we have demonstrated that ESKD patients can achieve substantial weight loss comparable with non-ESKD patients during surgical treatment of morbid obesity as preparation to kidney transplantation. This was to our knowledge never demonstrated in a matched pair analysis. The aim of this study was to evaluate weight loss in the preparatory period, and after bariatric surgery, in morbidly obese patients with ESKD before kidney transplantation, compared with nonESKD morbidly obese patients.
In the literature, the most frequent cause for non-inclusion into the transplant waiting list is attributed to obesity (up to $30 \%$ ) [12]. Based on the analysis of 19,524 dialysis patients, patients with BMI $\geq 40 \mathrm{~kg} / \mathrm{m}^{2}$ were half as likely to undergo kidney transplantation than those with a BMI between 21 and $31 \mathrm{~kg} / \mathrm{m}^{2}$ [5]. Several obesity treatments were proposed. Those including behavioral modification (physical activity, dietary modification) result only in a mean of 5 to $15 \%$ weight loss, and that result was maintained only in 5.3 to $10.5 \%$ of participants during a 1-year observation [13]. Similarly, psychosocial interventions such as group-based diet, group physical activity are related to a $3.5-\mathrm{kg}$ weight loss in 6 months (95\% CI, -4.2 to -2.8 ) and $3.4 \mathrm{~kg}$ in 12 months $(95 \% \mathrm{CI},-$ 4.2 to -2.9 ) [14]. Among all weight loss intervention, surgical treatment was considered the most effective. Our results present significant reduction of BMI, similar to matched pairs without ESKD in the 1-year follow-up (Table 2). In other studies, patients undergoing RYGB lost $29.9 \%$ (95\% CI, $29.3-30.5 \%$ ) more of their baseline weight at the 1 year follow-up than the non-surgical matches [15]. For LSG, 1year weight loss was $23.4 \%$ (95\% CI, 21.8-24.7\%) [15]. As compared with behavioral modifications, reduction of BMI at 1 year was $-11.3 \mathrm{~kg} / \mathrm{m}^{2}$ for OAGB, $-10.1 \mathrm{~kg} / \mathrm{m}^{2}$ for sleeve gastrectomy (SG), and $-9.0 \mathrm{~kg} / \mathrm{m}^{2}$ for RYGB [16]. The achieved weight loss was maintained for a long time (28.6\% (95\% CI, 19.5-37.6\%) of their initial weight at 10 years) [15]. 
Table 2 Weight loss in ESKD and non-ESKD patients

\begin{tabular}{|c|c|c|c|}
\hline & ESKD group & Non-ESKD group & $p$ \\
\hline Maximum BMI (mean/median) & $43.2 / 43.5$ & $43.6 / 41.5$ & 0.663 \\
\hline Initial BMI (mean/median) & $38.7 / 37.9$ & $38.4 / 37.9$ & 0.973 \\
\hline$\Delta \mathrm{BMI}$ & 4.36 & 5.13 & 0.608 \\
\hline Percentage BMI loss & $10 \%$ & $11 \%$ & 0.640 \\
\hline$\%$ EBMIL & $22 \%$ & $25 \%$ & 0.650 \\
\hline \multicolumn{4}{|c|}{ Follow-up visit 1 month after surgery $(n=20 / 20)$} \\
\hline BMI & $33.8 / 33.5$ & $34.3 / 34.2$ & 0.883 \\
\hline$\Delta \mathrm{BMI}$ & 4.4 & 4.1 & 0.763 \\
\hline Percentage BMI loss & $11 \%$ & $10 \%$ & 0.651 \\
\hline$\%$ EBMIL & $33 \%$ & $30 \%$ & 0.586 \\
\hline \multicolumn{4}{|c|}{ Follow-up visit 3 months after surgery $(n=18 / 20)$} \\
\hline BMI & 24.8 & $32 / 32$ & 0.073 \\
\hline$\Delta \mathrm{BMI}$ & 8.4 & 6.5 & 0.077 \\
\hline Percentage BMI loss & $22 \%$ & $17 \%$ & 0.038 \\
\hline$\%$ EBMIL & $65 \%$ & $49 \%$ & 0.032 \\
\hline \multicolumn{4}{|c|}{ Follow-up visit 6 months after surgery $(n=18 / 18)$} \\
\hline BMI & 22.8 & $29.4 / 29.4$ & 0.151 \\
\hline$\Delta \mathrm{BMI}$ & 10.3 & 8.6 & 0.228 \\
\hline Percentage BMI loss & $27 \%$ & $22 \%$ & 0.126 \\
\hline$\%$ EBMIL & $79 \%$ & $66 \%$ & 0.100 \\
\hline \multicolumn{4}{|c|}{ Follow-up visit 12 months after surgery $(n=14 / 17)$} \\
\hline BMI & 28.9 & $29.4 / 29.4$ & 0.748 \\
\hline$\Delta \mathrm{BMI}$ & 12.3 & 9.4 & 0.275 \\
\hline Percentage BMI loss & $25 \%$ & $24 \%$ & 0.716 \\
\hline$\%$ EBMIL & $90 \%$ & $68 \%$ & 0.190 \\
\hline
\end{tabular}

$n=$ number of patients in ESKD and non-ESKD group respectively
Those studies have shown that bariatric surgery not only can allow a 1-year substantial weight loss but also is the most effective way of achieving sustained weight reduction in obese patients [16]. The type of surgical procedure of choice in ESKD patients is still discussed. Our patients were qualified to a specific type of weight loss surgery according to the IFSO guidelines for the general population, which may in turn be inappropriate for ESKD patients [9]. Over the years, SG has
Fig. 1 The comparison of the percentage of excess BMI loss after bariatric surgery between ESKD and non-ESKD patients $(p<0.05$ statistically significant $)$

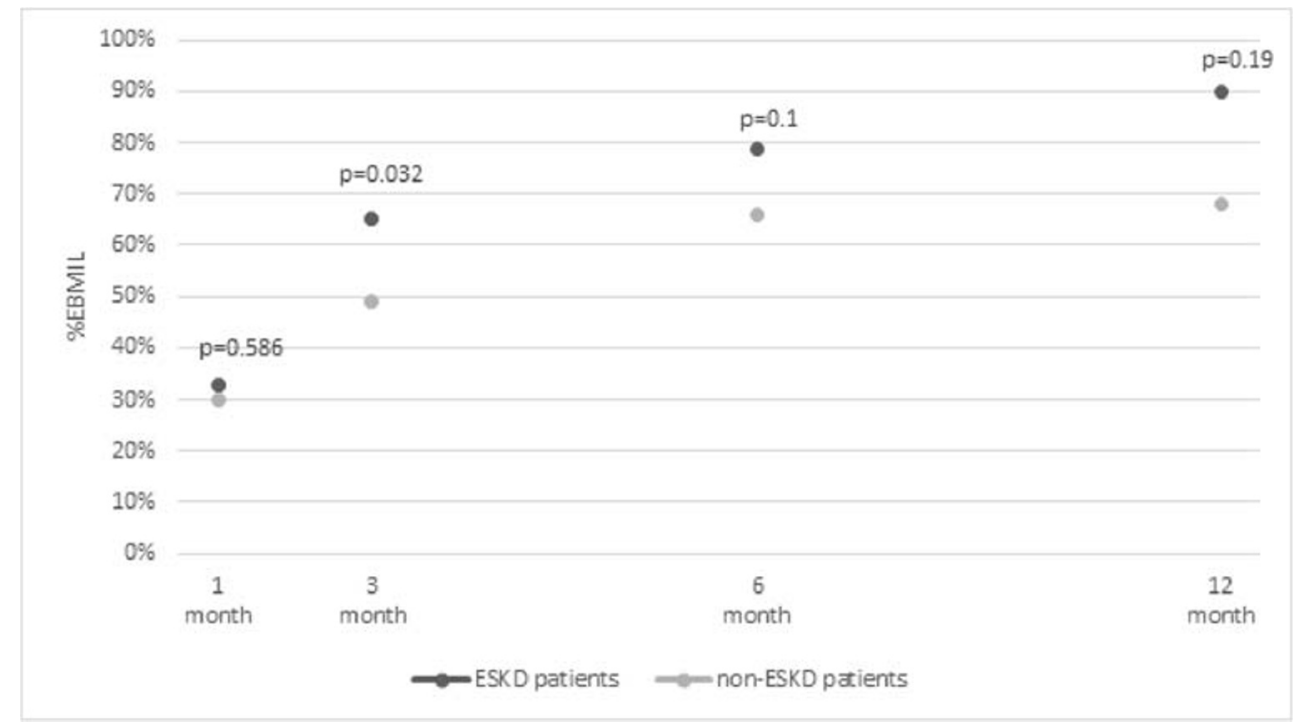


replaced RYGB in that group of patients because of its relatively safe profile $[17,18]$. Our national practice guidelines are not following those recent results [19, 20]. In morbidly obese patients with the indications for intestinal bypass methods, OAGB and RYGB were successfully implemented with the caution of hyperoxaluria presence during the rapid weight loss period and the risk of nephrolithiasis [21]. ESKD obese patients often fail to non-surgical intervention and are considered refractory to behavioral therapy. Bariatric surgery offers them not only a decrease in BMI but also an improvement of the altered kidney function and deceleration of the progression of renal diseases in patients with ESKD of various etiologies. Our matched pair analysis resulted in comparable weight loss in the preparatory period before bariatric surgery. Pretransplant renal replacement therapy of ESKD can influence the ability of patients to adhere to preoperative period weight loss instructions (i.e., steroids, osteoporosis) [22]. Despite those burdens, the results of the preparatory period did not differ significantly between the compared groups. They achieved $-4.36 \%$ and $-5.13 \%$ BMI loss in the preparatory period respectively, $p=0.608$. The ESKD patients lost $21.78 \%$ of excess BMI and non-ESKD lost $24.53 \%$ EBMI. Moreover, our ESKD patients strictly meet the mandatory weight loss criteria (the median preoperative total weight change was $-10.2 \%$ and $-11.6 \%$ in the ESKD and nonESKD groups respectively; $p=0.619$ ) [23]. The preparatory weight reduction was not impaired by comorbidities (in our material, no statistical difference between groups except from hypertension). In the literature, a satisfactory preoperative weight loss correlates positively with postoperative weight loss as well as weight loss after 1 year [24, 25]. Moreover, successful preoperative weight loss is associated with a significant decrease in perioperative complications in a systematic review on 4611 patients ( 2 studies on 1234 patients) [25].

In our study, ESKD patients have comparable postoperative weight loss to non-ESKD obese patients (Fig. 1). The groups did not differ significantly in postoperative weight loss measured during the 1-year follow-up (1-year BMI was $28.9 \mathrm{~kg} / \mathrm{m}^{2}$ vs $29.4 \mathrm{~kg} / \mathrm{m}^{2}, p=0.748$ and \%EBMIL $90.5 \%$ vs $67.5 \%, p=0.190$ in ESKD and non-ESKD patients respectively). This fact indicates the possibility of safe and effective weight loss similar to non-ESKD. Although in the literature ESKD patients experienced a higher risk of postoperative complications compared with those without kidney disease, the absolute complication rates were low and bariatric treatment is considered safe in that group of patients [26]. Interestingly, in our study, the weight loss and decrease in BMI are significantly higher in the first month following bariatric surgery. This can be related to changes in plasma adipocytokines following surgery and a positive correlation with lowering insulin resistance in ESKD patients [27]. Moreover, ESKD patients in that period lost more excessive weight and the relative cardiovascular risk is starting to decline faster than non-ESKD patients. It was proven that weight loss is related to remission of diabetes (remission rate up to $61 \%$ ), low-density lipoproteins (73\%), and blood pressure $(63 \%)[28,29]$. Not only weight loss but also resolution of ESKD-related comorbidities (diabetes mellitus, hypertension, hyperlipidemia, coronary heart disease, sleep apnea) is associated with metabolic and clinical benefits and lowers the risk of kidney transplantation.

According to the European Renal Best Practice Guideline recommendations, patients with a $\mathrm{BMI}>30 \mathrm{~kg} / \mathrm{m}^{2}$ should reduce weight before transplantation [19]. Literature data on the association of obesity and post-transplant graft function is conflicting. It was proven that obesity was associated with a higher risk of delayed graft function, graft loss, and lower patient and graft survival, but interestingly, obese individuals without comorbidities can experience similar survival to nonobese recipients [30-32]. However, often due to obesityassociated comorbidities, their access to the transplant list and transplantation is inferior to non-obese [5,33]. Bariatric surgery is considered as a safe method of obesity treatment in that specific group of patients and feasible as a bridge therapy to kidney transplantation [6, 34-36]. Additionally, weight loss after bariatric surgery may improve kidney function to an acceptable level and delay the qualification to dialysis therapy in patients undergoing bariatric surgery before ESKD development. It was proven that weight loss resulted in an improvement of proteinuria and albuminuria and normalization of the glomerular filtration rate [22]. For dialyzed ESKD patients, bariatric surgery can slow the progression and allows them to stay on the transplant waiting list. Eight of our patients were already successfully transplanted within a few months up to 3 years after bariatric surgery. The optimal interval between the bariatric procedure and kidney transplantation has not been established yet. Long-term follow-up after bariatric surgery can be important in setting the optimal time of transplantation in obese ESKD patients. Furthermore, pretransplant weight loss as a result of bariatric surgery can improve the prehabilitation process before kidney transplantation, and as a result improve the functional and physiological capacity for a fast recovery sooner after kidney transplantation. Larger, long-term studies are needed to analyze the durability of this improvement and the effects on renal transplantation outcomes.

Our study has the following limitations. First, the results need to be interpreted acknowledging that the effects of surgery may vary, based on the characteristics of the individual patient, i.e., age, sex, and pre-surgery BMI comorbidities. Second, the group size was small, and the analysis was performed retrospectively. Although we matched patients for type of bariatric procedure performed, there are many factors related to specific procedure qualifications which may impact upon the results. Third, follow-up was limited to 1 year, thus long-term results of bariatric surgery in that group of patients 
were not analyzed. Lastly, three different bariatric procedures are included in analysis, which blurs the difference of outcome related to procedure type [37]. Research aimed to indicate the most effective type of bariatric surgery in ESKD patients is needed.

\section{Conclusion}

Successful kidney transplantation requires elimination of possible pretransplant risks. Obesity is related to a higher risk of intra- and postoperative complications. Morbidly obese kidney transplantation candidates benefit from bariatric surgery and can be eagerly included in bariatric surgery weight loss programs. Bariatric surgery allows efficient pretransplantation weight loss results, and the procedures in ESKD patients seem as safe as previously published.

\section{Compliance with Ethical Standards}

Conflict of Interest The authors declare that they have no conflict of interest.

Ethical Approval Statement For this type of study, formal consent is not required.

Informed Consent Statement Informed consent does not apply.

Open Access This article is licensed under a Creative Commons Attribution 4.0 International License, which permits use, sharing, adaptation, distribution and reproduction in any medium or format, as long as you give appropriate credit to the original author(s) and the source, provide a link to the Creative Commons licence, and indicate if changes were made. The images or other third party material in this article are included in the article's Creative Commons licence, unless indicated otherwise in a credit line to the material. If material is not included in the article's Creative Commons licence and your intended use is not permitted by statutory regulation or exceeds the permitted use, you will need to obtain permission directly from the copyright holder. To view a copy of this licence, visit http://creativecommons.org/licenses/by/4.0/.

\section{References}

1. Iseki K, Ikemiya Y, Kinjo K, et al. Body mass index and the risk of development of end-stage renal disease in a screened cohort. Kidney Int. 2004;65(5):1870-6. https://doi.org/10.1111/j.15231755.2004.00582.x.

2. Nehus E. Obesity and chronic kidney disease. Curr Opin Pediatr. 2018;30(2):241-6. https://doi.org/10.1097/MOP. 0000000000000586

3. Lakkis JI, Weir MR. Obesity and kidney disease. Prog Cardiovasc Dis. 2018;61(2):157-67. https://doi.org/10.1016/j.pcad.2018.07. 005.

4. Friedman AN, Miskulin DC, Rosenberg IH, et al. Demographics and trends in overweight and obesity in patients at time of kidney transplantation. Am J Kidney Dis. 2003;41(2):480-7. https://doi. org/10.1053/ajkd.2003.50059.
5. Lassalle M, Fezeu LK, Couchoud C, et al. Obesity and access to kidney transplantation in patients starting dialysis: a prospective cohort study. PLoS One. 2017;12(5):e0176616. https://doi.org/10. 1371/journal.pone.0176616.

6. Proczko M, Pouwels S, Kaska L, et al. Applying enhanced recovery after bariatric surgery (ERABS) protocol for morbidly obese patients with end-stage renal failure. Obes Surg. 2019;29(4):1142-7. https://doi.org/10.1007/s11695-018-03661-y.

7. Potluri K, Hou S. Obesity in kidney transplant recipients and candidates. Am J Kidney Dis. 2010;56(1):143-56. https://doi.org/10. 1053/j.ajkd.2010.01.017.

8. Agarwal R. Defining end-stage renal disease in clinical trials: a framework for adjudication. Nephrol Dial Transplant. 2016;31(6): 864-7. https://doi.org/10.1093/ndt/gfv289.

9. Fried M, Yumuk V, Oppert JM, et al. Interdisciplinary European guidelines on metabolic and bariatric surgery. Obes Surg. 2014;24(1):42-55. https://doi.org/10.1007/s11695-013-1079-8.

10. Kaska L, Sledzinski T, Chomiczewska A, et al. Improved glucose metabolism following bariatric surgery is associated with increased circulating bile acid concentrations and remodeling of the gut microbiome. World J Gastroenterol. 2016;22(39):8698-719. https://doi.org/10.3748/wjg.v22.i39.8698.

11. Brethauer SA, Kim J, El Chaar M, et al. Standardized outcomes reporting in metabolic and bariatric surgery. Surg Obes Relat Dis. 2015;11:489-506. https://doi.org/10.1016/j.soard.2015.02.003.

12. Toapanta-Gaibor NG, Suñer-Poblet M, Cintra-Cabrera M, et al. Reasons for noninclusion on the kidney transplant waiting list: analysis in a set of hemodialysis centers. Transplant Proc. 2018;50(2):553-4. https://doi.org/10.1016/j.transproceed.2017.09. 066.

13. Ramage S, Farmer A, Eccles KA, et al. Healthy strategies for successful weight loss and weight maintenance: a systematic review. Appl Physiol Nutr Metab. 2014;39(1):1-20. https://doi.org/10. 1139/apnm-2013-0026.

14. Borek AJ, Abraham C, Greaves CJ, et al. Group-based diet and physical activity weight-loss interventions: a systematic review and meta-analysis of randomised controlled trials. Appl Psychol Heal Well-Being. 2018;10(1):62-86. https://doi.org/10.1111/aphw. 12121.

15. Maciejewski ML, Arterburn DE, Van Scoyoc L, et al. Bariatric surgery and long-term durability of weight loss. JAMA Surg. 2016;151(11):1046-55. https://doi.org/10.1001/jamasurg.2016. 2317.

16. Padwal R, Klarenbach S, Wiebe N, et al. Bariatric surgery: a systematic review and network meta-analysis of randomized trials. Obes Rev. 2011;12(8):602-21. https://doi.org/10.1111/j.1467789X.2011.00866.x.

17. Sheetz KH, Woodside KJ, Shahinian VB, et al. Trends in bariatric surgery procedures among patients with ESKD in the United States. Clin J Am Soc Nephrol. 2019;14(8):1193-9. https://doi.org/10. 2215/CJN.01480219.

18. Bouchard P, Tchervenkov J, Demyttenaere S, et al. Safety and efficacy of the sleeve gastrectomy as a strategy towards kidney transplantation. Surg Endosc. July 2019:1-8. https://doi.org/10.1007/ s00464-019-07042-z.

19. Abramowicz D, Cochat P, Claas FHJ, et al. European Renal Best Practice Guideline on kidney donor and recipient evaluation and perioperative care: figure 1. Nephrol Dial Transplant. 2015;30(11): 1790-7. https://doi.org/10.1093/ndt/gfu216.

20. Kasiske BL, Cangro CB, Hariharan S, et al. The evaluation of renal transplantation candidates: clinical practice guidelines. Am J Transplant. 2001;1(Suppl 2):3-95. http://www.ncbi.nlm.nih.gov/ pubmed/12108435. Accessed 25 Octob 2019

21. Camilleri B, Bridson JM, Sharma A, et al. From chronic kidney disease to kidney transplantation: the impact of obesity and its 
treatment modalities. Transplant Rev. 2016;30(4):203-11. https:// doi.org/10.1016/j.trre.2016.07.006.

22. Bolignano D, Zoccali C. Effects of weight loss on renal function in obese CKD patients: a systematic review. Nephrol Dial Transplant. 2013;28(Suppl 4):iv82-98. https://doi.org/10.1093/ndt/gft302.

23. Thorell A, MacCormick AD, Awad S, et al. Guidelines for perioperative care in bariatric surgery: enhanced recovery after surgery (ERAS) society recommendations. World J Surg. 2016;40(9): 2065-83. https://doi.org/10.1007/s00268-016-3492-3.

24. Livhits M, Mercado C, Yermilov I, et al. Does weight loss immediately before bariatric surgery improve outcomes: a systematic review. Surg Obes Relat Dis. 2009;5(6):713-21. https://doi.org/ 10.1016/j.soard.2009.08.014.

25. Cassie S, Menezes C, Birch DW, et al. Effect of preoperative weight loss in bariatric surgical patients: a systematic review. Surg Obes Relat Dis. 7(6):760-7; discussion 767. https://doi.org/10.1016/j. soard.2011.08.011.

26. Cohen JB, Tewksbury CM, Torres Landa S, et al. National postoperative bariatric surgery outcomes in patients with chronic kidney disease and end-stage kidney disease. Obes Surg. 2019;29(3):97582. https://doi.org/10.1007/s11695-018-3604-2.

27. Serra A, Granada ML, Romero R, et al. The effect of bariatric surgery on adipocytokines, renal parameters and other cardiovascular risk factors in severe and very severe obesity: 1-year followup. Clin Nutr. 2006;25(3):400-8. https://doi.org/10.1016/j.clnu. 2005.11.014

28. Aminian A, Daigle CR, Romero-Talamás H, et al. Risk prediction of complications of metabolic syndrome before and 6 years after gastric bypass. Surg Obes Relat Dis. 10(4):576-82. https://doi.org/ 10.1016/j.soard.2014.01.025.

29. Tham JC, le Roux CW, Docherty NG. Cardiovascular, renal and overall health outcomes after bariatric surgery. Curr Cardiol Rep. 2015;17(5) https://doi.org/10.1007/s11886-015-0588-6.
30. Hill CJ, Courtney AE, Cardwell CR, et al. Recipient obesity and outcomes after kidney transplantation: a systematic review and meta-analysis. Nephrol Dial Transplant. 2015;30(8):1403-11. https:// doi.org/10.1093/ndt/gfv214.

31. Lafranca JA, IJermans JNM, Betjes MGH, et al. Body mass index and outcome in renal transplant recipients: a systematic review and meta-analysis. BMC Med. 2015;13:111. https://doi.org/10.1186/ s12916-015-0340-5.

32. Guillaume A, Queruel V, Kabore R, et al. Risk factors of early kidney graft transplantectomy. Transplant Proc. 2019; https://doi. org/10.1016/j.transproceed.2019.07.027.

33. Diwan TS, Lee TC, Nagai S, et al. Obesity, transplantation, and bariatric surgery: an evolving solution for a growing epidemic. Am J Transplant. https://doi.org/10.1111/ajt.15784.

34. Jamal MH, Corcelles R, Daigle CR, et al. Safety and effectiveness of bariatric surgery in dialysis patients and kidney transplantation candidates. Surg Obes Relat Dis. 2015;11(2):419-23. https://doi. org/10.1016/J.SOARD.2014.09.022.

35. Ahmed MH, Byrne CD. Bariatric surgery and chronic kidney disease: an intriguing relationship. Nephrol Dial Transplant. 2010;25(12):4117-8. https://doi.org/10.1093/ndt/gfq595.

36. Al-Bahri S, Fakhry TK, Gonzalvo JP, et al. Bariatric surgery as a bridge to renal transplantation in patients with end-stage renal disease. Obes Surg. 2017;27(11):2951-5. https://doi.org/10.1007/ s11695-017-2722-6.

37. Mahawar K, Parmar C, Graham Y. Procedure and patient selection in bariatric and metabolic surgery. Minerva Chir. 2019; https://doi. org/10.23736/S0026-4733.19.08121-5.

Publisher's Note Springer Nature remains neutral with regard to jurisdictional claims in published maps and institutional affiliations. 